\title{
Autoxidation of Hydrocarbons in the Presence of Boric Acids Decomposition of Aromatic Hydroperoxides*
}

\author{
by Hiroshi Sakaguchi**, Yoshio Kamiya**, and Nobuto Ohta**
}

\begin{abstract}
Summary: The autoxidations of aromatic hydrocarbons are inhibited by the addition of boric acids and their derivatives, whereas the oxidations of aliphatic and alicyclic hydrocarbons are not inhibited and give selectively a boric ester of the corresponding secondary alcohol. In order to clarify these facts, teiralyl and cumyl hydroperoxides were decomposed by several types of boric acids and their derivatives. The rates of decompositions of these hydroperoxides were significantly accelerated by the boric acids and their derivatives, and $\gamma$-o-hydroxyphenylbutylaldehyde and phenol were produced selectively from tetralyl and cumyl hydroperoxide respectively. It was found that the faster the inhibition of the oxidation of tetralin, the higher the activity of the boric acids and their derivatives in the decomposition of tetralyl hydroperoxide. The acid strength of the boric acids was found to be much larger than that known as Brönsted acids. It was concluded that the boric acids acted as Lewis acids and not as Brönsted acids in the decomposition of aromatic hydroperoxides.
\end{abstract}

\section{Introduction}

In 1951, Bashkirov ${ }^{1)}$ found that the autoxidations of alkanes in the presence of boric acids gave secondary alcohols with high selectivity having the same carbon numbers with the parent hydrocarbons. Since then, the oxidations of hydrocarbons with boric acid have been studied extensively. Industrially, the productions of secondary aliphatic alcohols with $12 \sim 16$ carbons from $n$-paraffins and of cyclohexanol from cyclohexane by the boric acid catalysed oxidations have received much attention'). It is understood that the boric acids react with nonaromatic hydroperoxides, the primary oxidation products from hydrocarbons, to give boric esters selectively and prevent the further oxidations of the alcohol.

However, a small amount of aromatic hydrocarbons is known to inhibit the boric acid catalysed oxidations of aliphatic hydrocarbons $\left.{ }^{3}, 4\right)$. Drozdova and Bashkirov attributed this inhibition to the formation of phenol and, in fact, Illingworth and Lester ${ }^{6}$ ) found phenol in the oxidation products of cumene. However, phenol was not analysed quantitatively and the question why phenol was produced in the presence of boric acids is not yet dissolved.

* Received November 2, 1971.

* Department of Reaction Chemistry, Faculty of Engineering, The Univercity of Tokyo (Hongo, Tokyo, Japan)
In this paper, we studied the decompositions of aromatic hydroperoxides by boric acids (and their derivatives) and could demonstrate an almost quantitative formation of phenolic compounds which must be responsible for the inhibition of oxidations of hydrocarbons. It was also suggested that the boric acids acted as Lewis acids in the decomposition of hydroperoxides.

\section{Results and Discussion}

\subsection{Oxidations of Tetralin and Di-n. butylether}

In order to confirm the inhibiting effect of aromatic compounds in the oxidations in the presence of boric acids, tetralin was oxidized in propionic acid in the presence of four types of boric acids. As shown in Fig. 1, the rate of oxygen absorption by tetralin is decreased by the addition of boric acid. It was also found that the slower the oxidation, the lower the yield of tetralyl hydroperoxide (THP). In order to compare with aromatic compounds, di-n-butylether was oxidized in propionic acid in the presence and absence of boric acids as shown in Table 1. The presence or absence of boric acid gave no fundamental differences in the rates of oxidations and accumulation of hydroperoxides.

\subsection{Decomposition of Tetralyl and Cumyl Hydroperoxides}

Although THP was scarcely decomposed in

Volume 14, No. 1, May 1972 


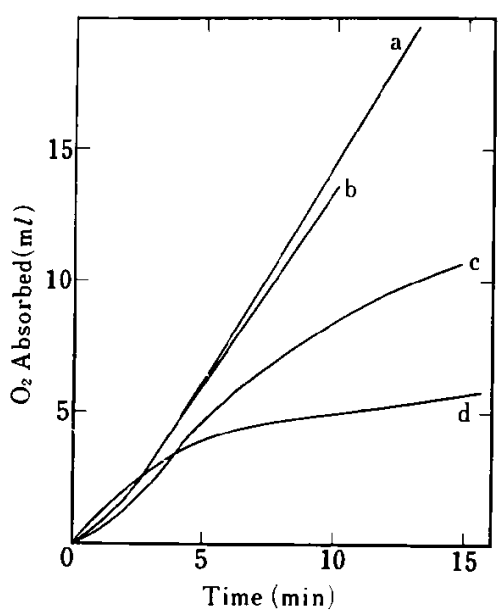

a: none b: $\left(n-\mathrm{C}_{15} \mathrm{H}_{37} \mathrm{O}\right)_{3} \mathrm{~B} \quad \mathrm{C}: \mathrm{H}_{3} \mathrm{BO}_{3} \quad \mathrm{~d}: \mathrm{B}_{2} \mathrm{O}_{3}$

Fig. 1 Autoxidation of Tetralin in the Presence of Boric Acids

Table 1 Autoxidation of di-n-Butylether at $80^{\circ} \mathrm{C}$

\begin{tabular}{|c|c|c|c|}
\hline $\begin{array}{c}\text { Catalyst } \\
(0.1 \mathrm{~mol} / \mathrm{l})\end{array}$ & $\begin{array}{l}-\mathrm{dO}_{2} / \mathrm{dt} \times 10^{5} \\
(\mathrm{~mol} / l \cdot \mathrm{sec})\end{array}$ & $\begin{array}{l}\text { I.P.a) } \\
(\mathrm{min})\end{array}$ & $\mathrm{ROOT} / \Delta \mathrm{O}$ \\
\hline \multicolumn{4}{|c|}{ Neat di-n-Butylether, $[A \mathrm{IBN}]=1.0 \times 10^{-2} \mathrm{~mol} / l$} \\
\hline $\begin{array}{l}\text { None } \\
\mathrm{H}_{3} \mathrm{BO}_{3} \\
\mathrm{HBO}_{2} \\
\left.\mathrm{~B}_{2} \mathrm{O}_{3} \mathrm{~b}\right) \\
\left(n-\mathrm{C}_{4} \mathrm{H}_{9} \mathrm{O}\right)_{3} \mathrm{~B} \\
\left(n-\mathrm{C}_{18} \mathrm{H}_{37} \mathrm{O}\right)_{3} \mathrm{~B}\end{array}$ & $\begin{array}{l}1.19 \\
0.98 \\
0.92 \\
1.00 \\
1.09 \\
1.14\end{array}$ & $\begin{array}{l}13.5 \\
13.5 \\
13 \\
3.5 \\
18 \\
11.5\end{array}$ & $\begin{array}{l}0.732 \\
0.933 \\
0.808 \\
0.648 \\
0.834 \\
0.686\end{array}$ \\
\hline \multicolumn{4}{|c|}{$\begin{aligned} \text { In Propionic Acid, } & {\left[\left(n-\mathrm{C}_{4} \mathrm{H}_{9}\right)_{2} \mathrm{O}\right]=2.97 \mathrm{~mol} / l } \\
& {[\mathrm{AIBN}]=7.5 \times 10^{-3} \mathrm{~mol} / l }\end{aligned}$} \\
\hline $\begin{array}{l}\text { None } \\
\mathrm{H}_{3} \mathrm{BO}_{3} \\
\left.\mathrm{~B}_{2} \mathrm{O}_{3} \mathrm{~b}\right) \\
\left(n-\mathrm{C}_{18} \mathrm{H}_{37} \mathrm{O}\right)_{3} \mathrm{~B}\end{array}$ & $\begin{array}{r}1.23 \\
1.42 \\
1.67 \\
0.99\end{array}$ & $\begin{array}{r}32 \\
6.5 \\
12.5 \\
15.5\end{array}$ & $\begin{array}{l}1.07 \\
1.03 \\
0.674 \\
0.984\end{array}$ \\
\hline
\end{tabular}

a) Induction Period

b) $5 \times 10^{-2} \mathrm{~mol} / \mathrm{l}$

a few hours by boric acids under nitrogen at $80^{\circ} \mathrm{C}$ in chlorobenzene or dodecane solutions, it was rapidly decomposed in propionic acid solvent. On the other hand, THP was stable in propionic acid in the absence of boric acids. Fig. 2 shows the rates of decomposition of THP by five types of boric acids in propionic acid. The boric acids should be stable and not change under the reaction conditions employed here. The rate of decomposition was pseudo-first order in THP. The deactivation of the catalysts was not observed. The boron trioxide had the highest activity and it gave the half life of only $4 \mathrm{~min}$. The tri- $n$-octadecyl borate gave the half life of $265 \mathrm{~min}$ and the lowest activity among the five catalysts used. But this is still faster than the non-catalysed decomposition, where the half life of THP was obtained as $310 \mathrm{~min}$.

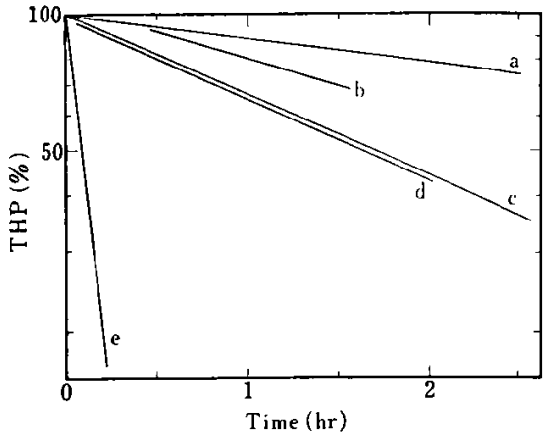

THP $1 \times 10^{-1} \mathrm{~mol} / l$, Boric acid $1 \times 10^{-1} \mathrm{~g}$-atom $/ l$, $80^{\circ} \mathrm{C}$, Propionic acid solvent

a: $\left(n-\mathrm{C}_{18} \mathrm{H}_{37} \mathrm{O}\right)_{3} \mathrm{~B}, \quad$ b: $\left(n-\mathrm{C}_{4} \mathrm{H}_{9} \mathrm{O}\right)_{3} \mathrm{~B}, \quad$ c: $\mathrm{HBO}_{2}$, d: $\mathrm{H}_{3} \mathrm{BO}_{3}$, e: $\mathrm{B}_{2} \mathrm{O}_{3}$

Fig. 2 Decomposition of THB in the Presence of Boric Acids

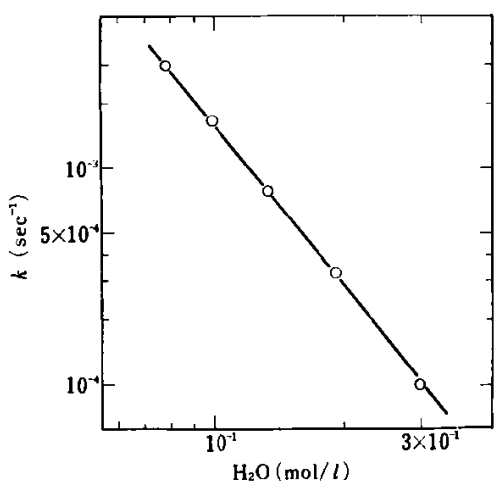

THP $1 \times 10^{-1} \mathrm{~mol} / l, \quad \mathrm{~B}_{2} \mathrm{O}_{3} \quad 5 \times 10^{-2} \mathrm{~mol} / l, \quad 80^{\circ} \mathrm{C}$, Propionic acid solvent

Fig. 3 Inhibition Effect of Water on the Decomposition of THP

Fig. 1 and 2 indicate that the higher the activity of the catalyst in the decomposition of THP, the slower the rate of oxidation of tetralin.

The effects of solvents on the rate of decomposition of THP were studied using boron trioxide as catalyst. In butyric acid, the rate was as fast as in propionic acid, but the rate became very slow in $n$-butyl alcohol with the half life of 4.5 $\mathrm{hr}$, and THP was scarcely decomposed in di- $n$ butylether.

It was found that water retarded the decomposition of THP in propionic acid in the presence of boron trioxide. Fig. 3 shows the effect of added water on the rate of decomposition of THP. This inhibiting effect of water may be attributed to the following equilibrium.

$$
\mathrm{B}_{2} \mathrm{O}_{3}+\mathrm{H}_{2} \mathrm{O} \rightleftharpoons 2 \mathrm{HBO}_{2}
$$

As shown in Fig. 2, the rate of decomposition of THP by metaboric acid is more than 20 times as slow as that in the presence of boron trioxide. 
Table 2 Decomposition Products of THP

\begin{tabular}{|c|c|c|c|c|}
\hline Run No. & 1 & 2 & 3 & 4 \\
\hline $\begin{array}{l}\text { Temperature, }{ }^{\circ} \mathrm{C} \\
{[\text { THP], mol } / l} \\
\text { Catalyst } \\
\text { mol } / l \\
\text { Solvent }\end{array}$ & $\begin{array}{c}80 \\
1.0 \times 10^{-1} \\
\mathrm{~B}_{2} \mathrm{O}_{3} \\
5 \times 10^{-2} \\
\mathrm{C}_{2} \mathrm{H}_{5} \mathrm{COOH}\end{array}$ & $\begin{array}{c}80 \\
7.2 \times 10^{-2} \\
\mathrm{~B}_{2} \mathrm{O}_{3} \\
5 \times 10^{-2} \\
\mathrm{C}_{2} \mathrm{H}_{5} \mathrm{COOH}+\text { Cumene }^{\mathrm{c})}\end{array}$ & $\begin{array}{c}80 \\
1.0 \times 10^{-1} \\
\mathrm{CoDe}_{2}^{\mathrm{a})} \\
2 \times 10^{-2} \\
\mathrm{C}_{2} \mathrm{H}_{5} \mathrm{COOH}\end{array}$ & $\begin{array}{c}30 \\
5.0 \times 10^{-2} \\
\mathrm{Co}-\mathrm{Nb}^{-2} \\
10^{-3} \\
\mathrm{C}_{6} \mathrm{H}_{5} \mathrm{Cl}\end{array}$ \\
\hline $\begin{array}{l}\text { Dihydronaphthalene } \\
\alpha \text {-Tetralol } \\
\alpha \text {-Tetralone } \\
\gamma \text {-o-Hydroxyphenylbutylaldehyde }\end{array}$ & $\begin{array}{l}\text { trace } \\
\text { trace } \\
94 . \overline{7} \%\end{array}$ & $\begin{array}{r}0.9 \% \\
1.4 \% \\
0.9 \% \\
93.9 \%\end{array}$ & $\begin{array}{l}53.0 \% \\
6.4 \% \\
-\end{array}$ & $\begin{array}{c}\text { trace } \\
54.6 \% \\
28.2 \% \\
-\end{array}$ \\
\hline
\end{tabular}

a) Cobalt Decanoate

b) Cobalt Naphthenate

c) $\mathrm{C}_{2} \mathrm{H}_{5} \mathrm{COOH} 40 \mathrm{ml}+$ Cumene $10 \mathrm{~m} l$

The decomposition products of THP were analysed in order to clarify the inhibiting effects of aromatic compounds in the boric acids catalysed oxidations. The results are summarised in Table 2. More than $90 \%$ of THP was converted by boron trioxide to $\gamma$-o-hydroxyphenylbutylaldehyde. On the contrary, when THP was decomposed by cobalt catalysts, $\alpha$-tetralol and $\alpha$-tetralone were the major products and no $\gamma$-o-hydroxyphenylbutylaldehyde was found.

The rate of decomposition of cumyl hydroperoxide (CHP) was much slower than THP but showed similar tendency towards boric acid catalysts. As shown in Fig. 4, when CHP was decomposed by boron trioxide at $80^{\circ} \mathrm{C}$ in propionic acid, phenol and acetone were obtained as the principal products and no acetophenone or cumyl alcohol were obtained. The last two compounds are the principal products when CHP was decomposed thermally or by transition metal catalysts. $t$-Butyl hydroperoxide was scarcely decomposed by boric acid catalysts under the same conditions.

Broich and Grasemann ${ }^{7}$ postulated the formation of active oxygen atom in the decomposition of cyclododecyl hydroperoxide by boron trioxide and orthoboric acid.

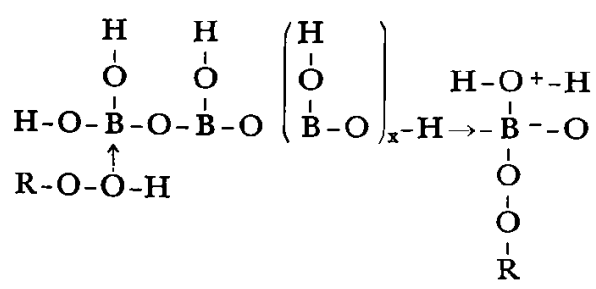$$
\rightarrow \mathrm{R}-\mathrm{O}-\mathrm{B}=\mathrm{O}+\mathrm{O}+\mathrm{H}_{2} \mathrm{O}
$$

In order to check the formation of active oxygen atom, CHP was decomposed by boron trioxide in the presence of small amounts of added tetralin. In this experiment, the oxidation products from tetralin such as $\alpha$-tetralol, $\alpha$-tet-

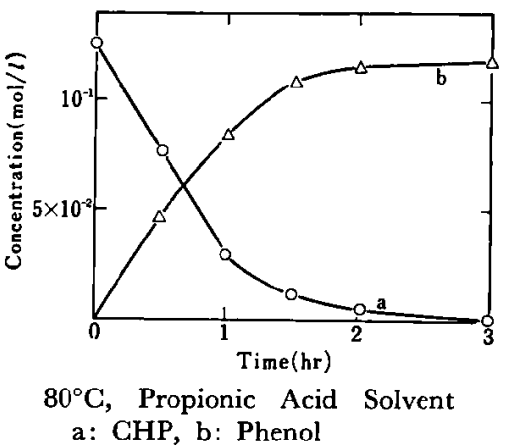

Fig. 4 Decomposition of CHP

ralone, dihydronaphthalene or $\gamma-0$-hydroxyphenylbutylaldehyde were not observed.

As shown above, boric acids accelerate the decomposition of aromatic hydroperoxides and give phenolic compounds, which must be responsible for the inhibition by aromatic hydrocarbons in the oxidations of aliphatic and alicyclic hydrocarbons in the presence of boric acids.

\subsection{Role and Activity of Boric Acids}

According to the results shown above, the role of boric acids in the decomposition of THP and $\mathrm{CHP}$ in propionic acid seems to be quite different from that on the decomposition of cyclododecyl hydroperoxide proposed by Broich and (Grasemann?), where boric acids gave borate ester of secondary alcohol of the corresponding hydroperoxide. The fact that the boric acids gave exclusively phenolic compounds from aromatic hydroperoxides implies that the boric

Table 3 Acid Strength of Boric Acids Measured by Indicators

\begin{tabular}{l|c}
\hline Boric Acid & $\mathrm{H}_{0}$ \\
\hline $\mathrm{H}_{8} \mathrm{BO}_{8}$ & $4.8 \sim 4.0$ \\
$\mathrm{HBO}_{2}$ & $4.0 \sim 3.3$ \\
$\mathrm{~B}_{2} \mathrm{O}_{3}$ & $1.5 \sim 0.8$ \\
$\left(n-\mathrm{C}_{4} \mathrm{H}_{9} \mathrm{O}\right)_{3} \mathrm{~B}$ & $4.0 \sim 3.3$ \\
$\left(n-\mathrm{C}_{18} \mathrm{H}_{37} \mathrm{O}\right)_{3} \mathrm{~B}$ & $4.0 \sim 3.3$ \\
\hline
\end{tabular}


acids act as acid catalyst. Kharasch and coworkers $^{8}$ ) reported the decomposition of THP by strong acid, such as perchloric acid, to $\gamma$ o-hydroxyphenylbutylaldehyde.

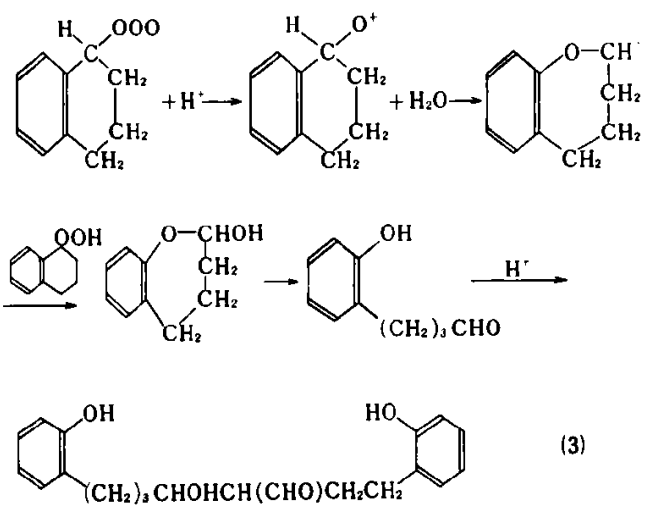

Furthermore, the decomposition of CHP by strong acid to produce phenol and acetone is a well known industrial "cumene process".

Thus we measured by using indicators the acid strength of each boric acid used in this experiment. The results are summarized in Table 3. The measured values are far stronger than what had been known as Brönsted acid. For example, orthoboric acid, which is the strongest Brönsted acid of all five boric acids used, has a dissociation constant of $\mathrm{pK}=9.00$, which is much weaker than the measured values shown in Table 3. Moreover, boron trioxide, the strongest acid in Table $\mathbf{3}$, is known as an amphoteric oxide. The presence or absence of propionic acid did not affect the acid strength of the boric acids. As described earlier, THP was quite stable in propionic acid in the absence of boric acids. However, the dissociation constant for propionic acid is $\mathrm{pK}=4.88$, which indicates that propionic acid is as strong Brönsted acid as orthoboric acid. Therefore, the boric acids must be working as Lewis acid in the decomposition of aromatic hydroperoxides.

Another support for this conclusion is the decomposition of THP by chloroacetic and trichloroacetic acids. These acids are stronger Brönsted acid, but the rates of decompositions of THP by these acids were much slower than that by boron trioxide.

The mechanism of boric acids catalysed decompositions of THP may be expressed by Eq. 3 by replacing $\mathrm{H}^{+}$with Lewis acid site. Alkoxy cation produced from hydroperoxide has an electrophilic oxygen, and so nucleophilic substituent must accelerates an intramolecular rearrangement reaction. o-Alkoxyphenyl group of THP rearranges faster than phenyl group of $\mathrm{CHP}$, and the rearrangement of methyl group in $t$-butyl hydroperoxide must be quite slow.

\section{Experimentals}

\subsection{Materials}

Tetralyl hydroperoxide was prepared by the autoxidation of tetralin at $50^{\circ} \mathrm{C}$ initiated by azobisisobutyronitrile. The products solution was concentrated by removing tetralin by distillation and THP was recrystallized from $n$-hexane several times. Commercial CHP was purified according to the standard procedure. Tetralin and di- $n$-butylether were shaken successively with sulfuric acid, water, alkali, and water, dried with calcium chloride, and then distilled under reduced pressure. Organic solvents were used as received without further purification. The water contents in these solvents were analysed quantitatively using Karl-Fisher method and found to be negligibly small. Boric acids and borates were used without further purification. The purity of each boric acid or borate was measured as follows. About 0.2 to $0.4 \mathrm{~g}$ of boric acid was weighed precicely into $100 \mathrm{~m} l$ of water, aliquot of mannitol was added, and then the mixture was titrated using $0.1 \mathrm{~N}$ sodium hydroxide solution. The purity was: $\mathrm{H}_{3} \mathrm{BO}_{3}, 96.8$; $\mathrm{HBO}_{2}, 95.4 ; \mathrm{B}_{2} \mathrm{O}_{3}, 99.3 ;\left(n-\mathrm{C}_{4} \mathrm{H}_{9} \mathrm{O}\right)_{3} \mathrm{~B}, 85.4$; $\left(n-\mathrm{C}_{18} \mathrm{H}_{37} \mathrm{O}\right)_{3} \mathrm{~B}$, more than $84.3 \%$.

\subsection{Kinetic Measurements}

The decompositions of THP and CHP were performed under dried nitrogen. The solutions were sampled out periodically and was titrated for unreacted hydroperoxide iodometrically. The rates of oxidations of tetralin and di- $n$ butylether were measured using a mercury manometer in a constant pressure closed system. The volume of oxygen absorbed was read every seconds or minutes, depending on the rate, and was plotted against the time. In every run, more than 15 points were plotted. In case of di- $n$-butylether, small induction period was observed, but a straight line was obtained after the induction period. The slope was read and calculated to the rate of oxidation.

\subsection{Product Determinations}

Analysis were performed by glc at $180^{\circ} \mathrm{C}$ using a $3 \mathrm{~m}$ column packed with $10 \%$ of PEG $20 \mathrm{M}$ on celite 545. Herium was used as a carrier gas at the speed of $40 \mathrm{~m} / / \mathrm{min} . \gamma$-o-hydro- 
xyphenylbutylaldehyde was analysed as 2,4-dinitrophenylhydrazone. Found: C, 55.53; $\mathrm{H}$, $4.60 ; \mathrm{N}, 16.22$, m.p. $135 \sim 137.5^{\circ} \mathrm{C}$. Calcd for $\left(\mathrm{NO}_{2}\right)_{2} \mathrm{C}_{6} \mathrm{H}_{3} \mathrm{NHNCH}\left(\mathrm{CH}_{2}\right)_{3} \mathrm{C}_{6} \mathrm{H}_{4} \mathrm{OH}: \mathrm{C}, 55.81$; $\mathrm{H}, 4.68 ; \mathrm{N}, 16.27 \%$. To confirm the quantitative recovery by this method, we checked using phenylpropionaldehyde which has similar structure with $\gamma$-o-hydroxyphenylbutylaldehyde. $98.2 \%$ of theoretical hydrazone of phenylpropionaldehyde could be obtained. Found: C, 57.60; H, 4.59; N, $17.67 \%$, m.p. $145.5^{\circ} \mathrm{C}$. Calcd for $\left(\mathrm{NO}_{2}\right)_{2} \mathrm{C}_{6} \mathrm{H}_{0} \mathrm{NHNCH}\left(\mathrm{CH}_{2}\right)_{2} \mathrm{C}_{6} \mathrm{H}_{5}$ : C, 57.32; H, 4.49; N, 17.83\%. Propionic acid had no inhibiting effect for the precipitation of hydrazone.

\subsection{Acid Strength}

Acid strength of each boric acid was measured using 12 kinds of indicators according to the standard procedures $^{9}$ ) at room temperature.

\section{References}

1) a) Bashkirov, A. N. et al., "The Oxidation of
Hydrocarbons in the Liquid Phase", 183 (1965) ed. by N. M. Emanuel, Pergamon Press, Oxford. b) Kamzolkin, V. V. Bashkirov, A. N., Neflekhimiya, 4, 599 (1964) (Chem. Abstr., 61, 13209a). c) Bashkirov, A. N., Alenteva, E. S., ibid., 4, 593 (1964) (Chem. Abstr., 61, 13218c). d) Bashkirov, A. N., Shiman Pal, Dokl. Akad. Nauk. SSSR, 128, 1175 (1959) (Chem. Abstr., 54, 7531h).

2) a) Stevens, N. J., Livingston, J. R., Jr., Chem. Eng. Progr., 64, 6 (1968). b) Alagy, J. et al., World Petroleum Congress, Mexico, P.D. 18 (1967).

3) Bashkirov, A. N. et al., Neftekhimiya, 4, 777 (1964) (Chem. Abstr., 62, 2645b).

4) Grasemann, H., Erdoel Kohle, Erdgas, Petrochem, 22, 715 (1969).

5) Drozdova, M. A., Bashkirov, A. N. et al., Dokl. Akad. Nauk. SSSR, 171, 345 (1966) (Chem. Abstr., 66, 2823ln).

6) Illingworth, G. E., Lester, G. W., Am. Chem.Soc. Chicago Meeting, September 11-15 (1967). But recently Grasemann ${ }^{4}$ reported not phenolic substances but quinones inhibited autoxidation of cyclododecane.

7) Broich F., Grasemann, H., Erdoel Kohle, Erdgas, Petrochem, 18, 360 (1965).

8) Kharasch, M. S., Burt, J. G., J. Org. Chem., 16, 150 (1951).

9) Tanabe, K., Takeshita, T., "Acid-Base Catalysis", 166 (1966), Sangyo Tosho Pub. Co. Ltd. 